\title{
Review and Critique of the book "Education and Experience" by John Dewey
}

\author{
Rasha Eldeeb ${ }^{1}$ \\ ${ }^{1}$ Assistant Professor, Department of Physiology, College of Medicine, Gulf Medical University (GMU) Ajman, \\ $U A E$.
}

\begin{abstract}
John Dewey is considered to be the philosophical father of experiential education or "progressive education", his theory of experience will continue to be read and discussed not only within education but also in philosophy and psychology.

In 'Experience and Education" Dewey started by saying that education had been divided into traditional and progressive education.

Dewey criticized traditional education for lacking the contribution of both society and students- by not addressing their needs - in planning and implementing the curricula and instead it focused on transmission of past experience irrelevant to the present and future circumstances. Also, Dewey argued that progressive education is too reactionary and takes a free approach without knowing how or why freedom can be used usefully in education stating that freedom for the sake of freedom is a weak philosophy of education and that educators should give students freedom guarded by proper discipline in democratic way that will not hinder their future learning.

According to Dewey's theory 'experience arises from the interaction of two principles -- continuity and interaction'. Continuity means that each experience takes from the past and has an effect on the future experience of the individual, while interaction refers to the situational and educator's influence on students' experience. Thus, Dewey argues that educators must first understand the nature of human experience, stating that the experience's value is judged by the effect that this experience has on the individual's present, future, and the extent to which the individual is able to contribute to society.

Dewey concluded that we must move beyond the paradigm war between different types of educations, and instead appreciate the name of education as such and above all admit and appreciate the fact that what we need is education with a theory of experience.
\end{abstract}

\section{Chapter 1 - Traditional vs. Progressive Education}

Dewey introduces the book with the idea that we like to think of either-or opposites recognizing that there are no intermediate possibilities, saying that education had divided just like -'either or' - into two camps 'traditional' and 'progressive'. Traditional education relies for its aims, methods of instruction, and discipline on things handed down from the past and transmitted in a static way to the pupils directly as an end product with no active participation of them. It is the cultural product of a society that assumed that the future would be much like the past. In contrast the new "progressive" education gives the chance for learning through experience as it relies on acquisition of skills as a means of attaining ends which are vital and appealing to students. It offers the expression and development of individuality and the "intimate and necessary" relationship between the "processes of actual experience and education." He also states that the so-called "progressive education" can be as dogmatic as the "traditional education", which advocates of the former would like replaced.

\section{Chapter 2 - The Need of a Theory of Experience}

Dewey admitted that we need to develop a new philosophy of education by realizing and appreciating the importance of incorporating and applying experience with quality in education that is to say "being both "agreeable" and "has a positive influence on later experiences". Although it may sound simple yet it's not easy to practice and may face many obstacles. As "Not all experience is educative" some are mis-educative" - if they are static, don't contribute to students' growth or don't lead students to understand later experience as they may halt or distort the growth of further future experiences. He stresses that traditional education does include experiences, but that often these experiences are defective. In this chapter he is also sowing the seeds of differentiating the "curriculum on paper" and the "curriculum in practice".

\section{Chapter 3 - Criteria of Experience}

Dewey stated that if we believe in democracy we will adapt the progressive education easily as it is "more in accord with the democratic ideal and its methods are more humane ", giving a better quality of human 
experience, which is more widely accessible and enjoyed, than do non-democratic and anti-democratic forms of social life" offered by the traditional education "being autocratic, with harsh methods". Dewey believes that we should support progressive education that applies the principle of continuity as a criterion, allows interaction and teach students in a manner consistent with their becoming positively interactive, democratic, and dynamic learners.

\section{Chapter 4 - Social Control}

Everyone is experiencing the social control in life which doesn't violate the personal freedom as long as it is agreed and accepted by the individual being part of the group and acting on behalf of the personal and group's interest. Dewey agrees that the educator should be a member of the group - being the most mature and experienced member, acting as a coach but not in autocratic way by being "just and fair", conducting the interactions and intercommunications which are the very life of the group as a community and teaching students manners that should be used while planning, participating, and interacting with others.

\section{Chapter 5 - The Nature of Freedom}

Dewey expressed that one problem of social control is the nature of freedom, especially the freedom of intelligence that is to say" freedom of observation and judgment exercised on behalf of purposes that are intrinsically worthwhile". Although physical freedom of movement does not automatically create freedom of intelligence -as "it's a mean, not an end" yet it is important for maintaining normal physical and mental health and allowing the teacher to know the student better and the student to know himself better. Freedom helps students learn how to control their impulses and desires as "the ideal aim of education is to create intelligent self-control". It gives them both the power to frame purposes, judge wisely and evaluate desires by the consequences which will result from acting upon them and the power to select and order means to carry chosen ends into operation.

\section{Chapter 6 - The Meaning of Purpose}

Freedom given by progressive education allows the students to identify desires and create a plan that makes those desires or ideas into realities as Dewey stated that freedom is "the power to frame purposes and to execute or carry into effect ", yet it should be self-controlled by having a foresight to judge the consequences of the goal or purpose. As a genuine purpose always starts with an impulse, progressive education helps students identify those impulses, observe the circumstances, and apply past experiences to formulate a plan of action and thus make that impulse an idea with a future. As Dewey said "A purpose is an end-view and a plan is a cooperative enterprise, not a dictation", so the teacher should be aware of the "capabilities, needs and past experiences" of students and should offer guidance, suggestions and allow their participation in developing a plan.

\section{Chapter 7 - Progressive Organization of Subject Matter}

Dewey said that since the material that was learned in traditional school was based on the past, some have mis-interpreted this as a call for progressive schools to ignore the past; however, the sound principle is to "Make acquaintance of and with the past as a mean of understanding the present." Dewey mentioned that "the weakest point in progressive schools is in the matter of selection and organization of intellectual subjectmatter" and stressed that it is part of the educator's experience to see that the problem [set for the student to study] relates to the present and within students' capacity and secondly, that it arouses in the learner an active search for information and for production of new ideas. In this way the new facts and ideas obtained will form the ground for further experiences in which new problems are presented "a continuous spiral". Also the discipline of scientific methods should be used to help students derive the significance of everyday experience.

\section{Chapter 8 - The Means and Goal of Education}

Dewey took for granted that "education must be based upon experience with intelligent development and direction in order to accomplish its ends both for the individual learner and for society." Saying that progressive education can only succeed when certain conditions are applied and adopted by the educators in practice as; the use of sound standards and methods for achieving its goals, which are based on providing the best educational experience possible to create confident, self-controlled, and capable students". Dewey stressed on that the fundamental issue is not of new versus old education but what is important is providing education with the philosophy of experience. "

\section{Critique of the Dewey's book "Education and Experience":}

My response to the book Education and Experience by Dewey will be in the form of conservative agreement, as I totally agree with Dewey in that both progressive and traditional educations provide 
experiences, so the issue is not whether experience is provided or not but what sort of experience the educator will use to provide the student with the knowledge. I can't have a reason to disagree with Dewey saying that the experience given should be an experience with quality, having a positive influence on the future experiences and preparing the student to share and participate in the community as an active member.

Dewey argues that providing the student with enjoyable learning experiences motivates them to continue learning; this motivation matters just as much as the knowledge that is learned which I totally agree with yet I'm a little bit conservative about admitting that this motivation is provided only by the progressive education as I can't deprive the traditional education from this privilege!, because according to my beliefs what is crucial in building students' motivation and arousing their ability to inquire, search and learn a new knowledge is the teacher's way of handling the lesson and discussing the subject. So I can't totally agree that the traditional education had failed in arousing the students' interest to learn, as I'm a product of traditional education yet I can't say that this way of teaching had killed the curiosity to know and the motivation to learn in me!

Dewey said that in traditional education the material to be learned was settled outside the present lifeexperience of the learner and having only to do with the past, I'm also conservative in agreeing totally with this as yes, maybe there was neither immediate application or practice of the knowledge nor emphasis on its relevance to the future in traditional medicine yet its relevance and importance was discovered, realized and practiced at the end maybe a bit later than in progressive education, so the goal was achieved in a delayed way but was achieved. Being a product of traditional education I can still remember that the pharmacology drugs taught to us in the $3^{\text {rd }}$ year were not relevant to us at that time although they were taught in the same phase with the Pathology and Parasitology, yet the absence of both patient contacts , vertical and horizontal integration deprived us from knowing the immediate relevance and application of it yet finally we got it at the $4^{\text {th }}, 5^{\text {th }}$ and $6^{\text {th }}$ year, that is to say it was achieved but delayed so I'm a little bit conservative in agreeing with Dewey totally in saying that the traditional education is completely strict to the past and have nothing to do with present or future.

I'm one hundred percent with what Dewey emphasized regarding the importance of intellectual freedom over just the temporary physical freedom, that is to say, the freedom of observation and of judgment exercised on behalf of purposes that are intrinsically worthwhile and that the role of the educator is to help the student strive forward, sometimes that would mean that the teacher takes away the student's temporary freedom in order to give them the important freedom of intelligence this is done by the teacher losing the position of external boss or dictator and take instead of it the role of being a leader of the group activities" being the most knowledgeable person in the group but not overpowering the group that the teacher needs to master". For me being an educator as well as a student in the process of continuous medical education, I can say that what really matter is the freedom of intelligence more than the physical freedom specially with presence of new way of teaching such as small group learning, peer learning and distance learning.

I believe as Dewey viewed that having the freedom does not mean to do whatever you want but it gives you the freedom to continue learning, which is very essential to both the students and educators and indeed very much relevant to their future career and their role in the community.

I'm absolutely convinced that the new method of teaching is not done so that teachers can do less work, as it is giving them more freedom in teaching, more chances to transfer an experience of quality in a continuous and interactive way to their students as well as improving students according to their individual needs.

Finally as Dewey said it's not a matter of new versus old education or traditional versus progressive education it is a matter of knowing what education is, value it and devote ourselves to finding out what conditions have to be satisfied in order to achieve it and the most important of all is realizing the importance and necessity of having education with a philosophy of experience.

\section{Is the book "Education and Experience" by Dewey's Applicable to my work?}

Using the philosophy of experience in education as mentioned by Dewey I found it very much applicable to my work. Teaching in a curriculum using the new education, it is essential for me to build the lesson plan based on a pre-requisite knowledge known and given to the student either in the same or previous years, so I'm taking the student's old experience and building on through giving new knowledge which is related to the present as well as future and being relevant to the student's present and future role in the community.

As an educator I use my personal experience as well as the student's old experience to let the student explore a new experience with vertical and horizontal integration of the knowledge that we both have.

Being a facilitator in PBL session I find that Dewey's principle is very much applicable not only regarding the use of experience of both teacher and student during discussing the PBL session but also the use of freedom in the discussion, and I don't mean the physical freedom, what is more important is the intellectual freedom given 
actually to both the student and the teacher, we can't argue about the freedom and experience given to the student in a continuous and interactive manner, what I mean by giving the educator the freedom in PBL session, surely I didn't mean to over control the group as an autocratic leader, no I meant giving the teacher the freedom of continuous learning, new knowledge in different specialties in a vertical and horizontal way of integration, not only this but also the teacher can practice this freedom during her or his process of continuous education such as the freedom given in distant education courses.

Also what Dewey mentioned about the role of educator in the group as being "the most mature and knowledgeable of them" without over dominating the group is very much applicable in being a facilitator in PBL trying to facilitate, guide the student toward discovering the new knowledge without being the leader and to assess the individual student abilities and learning needs.

Finally I totally agree with Dewey in applying not only the philosophy of experience in education but also the Democracy and freedom. 